\title{
Dramatic Interactions: Teaching Languages, Literatures and Cultures through Theater-Theoretical Approaches and Classroom Practices, edited by Colleen Ryan and Nicoletta Marini-Maio
}

\author{
Newcastle- upon -Tyne, Cambridge Scholar Publishing, 2011; \\ 405 pp; ISBN: 1-4438-26502
}

\section{Gabriella Caponi-Doherty}

This rich collection of essays is an apt follow up to the excellent previous volume on theatre and language pedagogy - Set the Stage! Teaching Italian through Theater. Theories, Methods, and Practices - published by the two co-editors - Colleen Ryan (Indiana University) and Nicoletta Marini-Maio (Dickinson College) - in 2009. While the previous volume was intended specifically to offer resources to teachers and students to help them incorporate the Italian theatre tradition into the language curriculum, this new collection seeks to confirm the effectiveness of using theatre for foreign language teaching and learning by offering examples where drama is used with other taught languages, such as French, German, Spanish, Italian, Portuguese, but also Romanian, Russian and Japanese. The book stems from the recent fertile pedagogical research carried out by Appiah, De Lauretis, Pavis, Pireddu and De Marinis - just to mention a few - which considers theatre both as a cultural product and as a constituent of a teaching philosophy on intercultural learning. For the editors, "Theatre is the literary genre which most actively engages the cultural learner and maximises his/her ability to appropriate what is other" (2). The contributors to this volume are educators who have been working in public or private institutions mainly in the US for many years, teaching foreign languages with theatrical texts and techniques or teaching drama in a foreign language. In all their essays the scholars' unshakeable faith in the power of theatre as a teaching tool to foster intercultural curiosity and understanding shines through.

The book is divided into five organic sections: "Why Theater? Practical and Philosophical Perspectives"; "Performance-Based Pedagogies for Foreign Languages and Cultures"; "Performance-Based Practices in the Foreign Language Classroom"; "Embodying the Cultural Other: Recreations, Improvisations, and Adaptations"; and "Theater in the Curriculum and in the Community: Program Design, Learning Objectives, and Assessment." In Section I, Les Essif (University of Tennessee) shows how something difficult like cultural uncertainty could be 
taught through performance exercises. Essif describes a very challenging class project, which entailed staging a performance, along with his students of Jean Giraudoux's 1930s play, La Guerre de Troie n'aura pas lieu - Tiger at the Gates in English. His objective was to discover "the twenty-first century theatrical community's relation to this "between wars" French play about personal, social and national conscience behind the Trojan War and behind all wars" (17). To explain the principle of uncertainty, after reading, discussing and condensing the text in a number of scenes, the students were asked to perform an exercise drawn from the tableau vivant. Essif distributed the roles, which included two extras for the main characters - Helen and Hector - , and he did not inform the theatrical group as a whole about which character each actor played. Once the tableau vivant was completed, the students were asked to step back and to examine the depiction of the fixed scene in relation to their original condensed scene. In the subsequent discussion it emerged that the exercise had attained quite a level of theatrical uncertainty - many of the actors had misidentified some of the characters and where not clear about the group's relation to their character. Quite surprisingly, however, it also became clear that the actors were comfortable with that level of uncertainty, so much so that they collectively decided to perform the play like a rehearsal to manifest the Brechtian alienation effect of the exercise. Through this innovative exercise the students accepted the uncertainty of the artistic process and it was through the theatricality of the play that they were able to grasp its cultural force and relevance and "in the final production, the actors were still rehearsing the performance of a cultural hypothesis, not delivering a cultural thesis" (21).

Dominica Radulescu (Washington and Lee University) after describing communication in foreign language as a performing act, moves on to describe the liberating possibilities available in performing in a foreign language and being in contact with a foreign culture. Talking about her 2007 experience as a Fulbright scholar in Romania where she taught feminist interpretation of canonical theatre works, she describes her realization that she "had become too comfortable in [her] Amerocentric feminism" (54) and had to reacquire "foreignness" in order to question herself.

Bettina Matthias (Middlebury College), instead, wrestles with the irksome question of switching the traditional language department's focus on literary studies in favour of cultural studies and signals the necessity of finding new ways to teach literary texts.

Sections II, III and IV contain a rich variety of experiences on the use of theatre texts and techniques to acquire a greater cultural awareness. For instance, the original use of the Performance Cycle to underscore language acquisition and foster a "meaningful awareness of the target culture" (88), used by Patricia Sobral (Brown University) in her Portuguese class, addresses the problem that foreign language classes are not drama classes and that language teachers are not necessarily trained in the performing arts. Or the challenging case study described by Yumiko Hashimoto (University of South Wales) in which drama techniques and principles - specifically the method of Hirata Oriza's 
"contemporary colloquial theatre" - were used in a 2002 advanced Japanese oral course to develop appropriate and versatile linguistic and communication techniques, so essential in Japanese society where there are many levels of linguistic politeness and where inappropriate speech style is penalised more severely than in other societies.

Finally Section V includes three essays which, albeit diverse, are connected by the concept of drama as catalyst. Colleen Ryan (Indiana University) deals with Italian curriculum development, describing the Goldoni project which was a "formal attempt to integrate one theatrical author and text into the entire Italian Studies curriculum at a medium-sized private research university during the spring semester of 2007" (329).

Laura Miccoli (Universidad Federal De Minas Gerais) addresses the lack of specific guidelines on how to conduct valid and reliable assessment of drama-based language courses, which have become an alternative to traditional courses of English as a second language.

In the last essay of the book, Thomas Simpson (Northwestern University) relates a five-week residency of the Teatro delle Albe and the tour of Marco Paolini at Northwestern, and the rippling effect they had which extended far beyond the boundaries of Chicago and the enhancement of Italian contemporary culture in the US.

The book, with a solid theoretical basis supported by a wealth of distinctive examples of class practices and experiments, is inspiring: a cohesive work which, by investigating drama and performance as an object of study and exploring the pedagogical benefits of a cross-disciplinary approach to language study, will definitely encourage a greater incorporation of theatrical texts and techniques in foreign language courses at every level. 